\title{
The incidence of stroke among selected patients undergoing elective posterior lumbar fusion: a retrospective cohort study
}

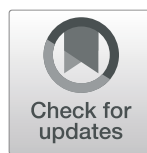

Patrick J. Arena ${ }^{1 *} \mathbb{D}$, Jingping $\mathrm{Mo}^{2}$, Charu Sabharwal ${ }^{3}$, Elizabeth Begier ${ }^{3}$, Xiaofeng Zhou', Alejandra Gurtman³ Qing Liư ${ }^{4}$, Rongjun Shen ${ }^{1}$, Charles Wentworth ${ }^{1}$ and Kui Huang ${ }^{1}$

\begin{abstract}
Background: Although stroke is a rare complication among spinal surgery patients, the recognition of this adverse event is critical given the aging population undergoing surgical procedures. The objective of this study was to estimate the incidence of stroke among selected adults undergoing elective posterior lumbar fusion (PLF) during various post-operative risk windows and among different subgroups.

Methods: A retrospective cohort study using a longitudinal electronic healthcare record (EHR) database was conducted from January 1, 2007 to June 30, 2018. Elective PLF, stroke, and select clinical characteristics were defined based on International Classification of Disease codes. Patients aged 18 to 85 years with $\geq 183$ days of enrollment in the database prior to undergoing elective PLF were followed from the index date until the occurrence of stroke, death, loss to follow-up, or end of study period, whichever occurred first. The incidence of stroke was estimated in the following risk windows: index hospitalization, $\leq 30$ days, $\leq 90$ days, $\leq 180$ days, and $\leq$ 365 days post-operation.

Results: A total of 43,063 patients were eligible for the study. The incidence of stroke following elective PLF was 0.29\% (95\% confidence interval [Cl]: 0.25, 0.35\%) during index hospitalization, $0.44 \%$ ( $95 \%$ Cl: $0.38,0.50 \%) \leq 30$ days, $0.59 \%$ (95\% Cl: $0.52,0.67 \%) \leq 90$ days, $0.76 \%$ (95\% Cl: $0.68,0.85 \%) \leq 180$ days, and $1.12 \%$ (95\% Cl: $1.03,1.23 \%) \leq 365$ days post-operation. Stratified analyses revealed that older patients had a higher incidence of stroke. Additionally, black patients had higher stroke incidences. Post-operative stroke incidence was higher among patients with a history of type 2 diabetes than among patients without such history; similarly, stroke incidence was higher among patients with a history of stroke compared to patients without such history.

Conclusions: The incidence of stroke following elective PLF using an EHR database in this study is slightly higher than that reported in the literature. Our results suggest that stroke risk modification prior to PLF may be important for patients who are older, black, type 2 diabetic, and/or have a history of stroke.
\end{abstract}

Keywords: Stroke, Posterior lumbar fusion, Epidemiology, Electronic healthcare records

\footnotetext{
* Correspondence: patrick.arena@pfizer.com

'Global Medical Epidemiology \& Big Data Analysis, Pfizer Inc, New York, NY,

USA

Full list of author information is available at the end of the article
}

(c) The Author(s). 2020 Open Access This article is licensed under a Creative Commons Attribution 4.0 International License, which permits use, sharing, adaptation, distribution and reproduction in any medium or format, as long as you give appropriate credit to the original author(s) and the source, provide a link to the Creative Commons licence, and indicate if changes were made. The images or other third party material in this article are included in the article's Creative Commons licence, unless indicated otherwise in a credit line to the material. If material is not included in the article's Creative Commons licence and your intended use is not permitted by statutory regulation or exceeds the permitted use, you will need to obtain permission directly from the copyright holder. To view a copy of this licence, visit http://creativecommons.org/licenses/by/4.0/. The Creative Commons Public Domain Dedication waiver (http://creativecommons.org/publicdomain/zero/1.0/) applies to the data made available in this article, unless otherwise stated in a credit line to the data. 


\section{Introduction}

Stroke was the second leading cause of death globally in 2016, with 177,196 stroke deaths and 731,256 incident cases in the United States (US) alone [1]. Stroke is associated with increased economic burden due to costs associated with treatment and post-stroke care as evidenced by a recent review by Rasjic et al. in which overall post-stroke care costs were estimated to be $\$ 4850$ per patient month in the US [2]. A 2017 review by Yang et al. concluded that hemorrhagic stroke after spine and joint surgeries is relatively rare, but it may cause serious consequences such as morbidity and mortality in the post-operative setting [3].

Although stroke is a rare complication among spinal surgery patients, the recognition of this adverse event is critical given the aging population undergoing surgical procedures. The volume of elective lumbar fusion procedures in the US has increased $62.3 \%$, from 122,679 cases in 2004 to 199,140 cases in 2015 ; these increases were greatest among those aged 65 years or older [4]. Furthermore, Etzioni et al. have demonstrated that the number of older people (i.e., those above the age of 65 years) undergoing surgery in general is increasing at a rate faster than the proportion of older people in the overall population [5]. The estimated incidence of post-operative stroke in the spinal surgery setting varies widely depending on the type of surgical procedure and patient population. For adults undergoing posterior lumbar fusions (PLFs), the incidence of stroke within 30 days post-surgery has been reported as approximately $0.2 \%$ [6-9], but there is little data during various post-operative risk windows.

It is important to have background epidemiology data about post-operative stroke during various risk windows and among different subgroups to contextualize safety data in clinical trials and to better understand stroke in the general population. This cohort study was thus designed to estimate the incidence of stroke among selected adults undergoing elective PLF using a large electronic healthcare record (EHR) database in the US. The objectives of this study were to 1 ) estimate the incidence of stroke among elective PLF patients in various post-operative time periods (including the index surgical hospitalization) and 2) characterize the cohort's demographic and clinical characteristics observed during the baseline to potentially identify those at increased risk of stroke.

\section{Methods}

\section{Study design}

A retrospective cohort study of adults undergoing elective PLF using a longitudinal EHR database, Optum EHR, was performed. Optum EHR partners directly with several multi-specialty medical groups, integrated delivery networks, and hospital chains throughout the US to extract their EHR data. By normalizing, validating, and aggregating the de-identified data, the database generates a longitudinal view of patient care and captures a comprehensive collection of demographic, clinical, operational, and financial information. As of June 30, 2017, Optum EHR reported having data on approximately 81 million unique patients. Furthermore, about $40 \%$ of the patient population was aged 50 years or older, with approximately $15 \%$ of patients 65 years of age or older. Almost one quarter (24\%) of the patients had at least 6 years of observation time within the database.

The study period was January 1, 2007 to June 30, 2018 with a length of follow-up equating to 365 days. The index surgical date was defined as the first date on or after January 1, 2007 that an adult had undergone an elective PLF. To incorporate a 183-day look-back window prior to the index surgery (for the purpose of excluding prevalent conditions), the earliest possible index surgical date was July 1, 2007. The latest index surgical date possible was June 30, 2017.

\section{Cohort formation}

Eligible patients were 18 to 85 years of age at the time of their first elective PLF. Furthermore, patients had 183 days of continuous enrollment within the database prior to their first elective PLF (i.e., the baseline period) as well as this index surgery being performed on the day of admission to the healthcare facility or the day after admission. PLF was identified using the following six International Classification of Diseases (ICD), Ninth Revision, Procedure Classification System (ICD-9-PCS) codes: 81.05 (dorsal and dorsolumbar fusion of the posterior column, posterior technique), 81.07 (lumbar and lumbosacral fusion of the posterior column, posterior technique), 81.08 (lumbar and lumbosacral fusion of the anterior column, posterior technique), 81.35 (refusion of dorsal and dorsolumbar spine, posterior column, posterior technique), 81.37 (refusion of lumbar and lumbosacral spine, posterior column, posterior technique), and 81.38 (refusion of lumbar and lumbosacral spine, anterior column, posterior technique).

To select for a healthy cohort that underwent inpatient elective surgeries, patients were excluded if they 1) underwent a major surgical procedure that occurred within 90 days prior to the index surgery; 2) had a surgical indication that was for an emergency procedure; 3) were pregnant; 4) were discharged on the same date of the index surgery (thereby indicating an outpatient procedure); 5) had any of the following conditions during the baseline period: anaphylactic reaction to a vaccine, cancer, end stage renal disease, congenital spleen anomalies, an immunosuppressive state, and/or receipt of corticosteroids or immunosuppressive medications; or 6) had any of the following conditions at the 
time of the index surgery: potential/presumed surgical site-related infection and/or spinal infection.

Stroke was defined based on the following ten ICD, Ninth Revision, Clinical Modification (ICD-9-CM) codes: 433.01 (occlusion and stenosis of basilar artery with cerebral infarction), 433.11 (occlusion and stenosis of carotid artery with cerebral infarction), 433.21 (occlusion and stenosis of vertebral artery with cerebral infarction), 433.31 (occlusion and stenosis of multiple and bilateral precerebral arteries with cerebral infarction), 433.81 (occlusion and stenosis of other specified precerebral artery with cerebral infarction), 433.91 (occlusion and stenosis of unspecified precerebral artery with cerebral infarction), 434.01 (cerebral thrombosis with cerebral infarction), 434.11 (cerebral embolism with cerebral infarction), 434.91 (cerebral artery occlusion, unspecified with cerebral infarction), and 436 (acute, but ill-defined, cerebrovascular disease). ICD-9-PCS and ICD-9-CM codes were mapped to corresponding ICD, Tenth Revision (ICD-10) codes using General Equivalence Mapping techniques in order to account for the switch to ICD-10 coding in 2015.

\section{Data management and analysis}

All analyses were descriptive and conducted in SAS (version 9.4, SAS Institute, Cary, NC, USA). Descriptive statistics were performed to characterize the cohort in terms of demographic and clinical characteristics at the baseline. Patients were followed from the cohort entry index date until the occurrence of stroke, death, loss to follow-up, or end of study period, whichever occurred first.

Incidence was defined as the number of new cases of stroke during each specified time interval divided by the total (stroke-free) population at the start of each time interval; thus, the incidences calculated here are incidence proportions. Crude incidence was calculated overall, and in the following stratifications: age, sex, race, length of hospital stay, and selected clinical characteristics. Incidence was also estimated in the following risk windows: index hospitalization (defined as the time interval from index surgery to discharge), $\leq 30$ days (i.e., 0 to 30 days), $\leq 90$ days (i.e., 0 to 90 days), $\leq 180$ days (i.e., 0 to 180 days), and $\leq 365$ days (i.e., 0 to 365 days) post-operation. For each post-operation period, incidence was calculated cumulatively; therefore, persons at risk and stroke events that were included in the preceding risk window were not excluded in the incidence calculation for the following risk window. Incidences were estimated with associated $95 \%$ confidence intervals (CIs), assuming a Poisson distribution.

Incidence rates were also produced and were calculated as the number of new cases of stroke during each specified time interval divided by the summed persontime of observation for the total (stroke-free) population at the start of each time interval. Although incidence rates are preferred over incidence proportions when there is long-term follow up (i.e., > 30 days), nearly all the literature identified in this area presented information in the form of incidence proportions; thus, only incidence proportions are presented in the Results in order to facilitate better comparisons with the literature. However, incidence rate information is contained in Additional file 1.

\section{Results}

Of the 80,796 patients who were 18 to 85 years of age with at least one record of elective PLF during the study period and adequate prior enrollment in the database, 37,733 met exclusion criteria; the most common reasons for exclusion were use of immunosuppressive medications (42\%), receipt of systemic corticosteroids (33\%), and a diagnosis of cancer (14\%) during the baseline. Ultimately, 43,063 patients were included for analysis; 42,966 patients had at least 365 days of follow-up from the index date (thereby indicating a low level of loss-tofollow-up in the study). The mean age was 59.4 years, and there were slightly more females $(52.22 \%)$ than males $(47.75 \%)$. The majority of the cohort members were white $(89.49 \%)$, while black (5.94\%) and Asian $(0.52 \%)$ members were less represented. The most prevalent medical conditions were type 2 diabetes (13.86\%), cardiac dysrhythmias (9.28\%), and chronic ischemic disease (9.00\%). Only 293 patients $(0.68 \%)$ had any history of stroke during the baseline. Dementia, individual digestive disorders, deep vein thrombosis, and pulmonary embolism were also rare (i.e., each less than $1.00 \%$ ). Moreover, the average length of hospital stay (for the index hospitalization) was 3.8 days. Lastly, no patients died during initial hospitalization; by the end of the study period, all-cause mortality was approximately $0.50 \%$. Table 1 shows the baseline demographics and clinical characteristics of the elective PLF patient population.

The crude incidence of stroke following elective PLF was $0.29 \%$ (95\% CI: $0.25,0.35 \%$ ) during index hospitalization, $0.44 \%$ (95\% CI: $0.38,0.50 \%) \leq 30$ days, $0.59 \%$ (95\% CI: 0.52 , $0.67 \%) \leq 90$ days, $0.76 \%(95 \%$ CI: $0.68,0.85 \%) \leq 180$ days, and $1.12 \%(95 \%$ CI: $1.03,1.23 \%) \leq 365$ days post-operation. Table 2 shows both crude and stratified stroke incidences in patients undergoing elective PLF.

Stratified analyses revealed that older patients consistently had higher incidences of post-operative stroke during all surgical risk windows. For example, the incidence of post-operative stroke $\leq 365$ days post-operation was $0.40 \%$ (95\% CI: $0.31,0.52 \%$ ) among those aged $\geq 18$ to 55 years, $0.91 \%$ (95\% CI: $0.74,1.10 \%)$ among those aged 56 to 65 years, $1.66 \%$ ( $95 \%$ CI: $1.43,1.91 \%$ ) among those aged 66 to 75 years, and $2.73 \%$ (95\% CI: $2.28,3.25 \%$ ) among those aged 76 to $<86$ years. Moreover, men had 
Table 1 Baseline demographics, clinical characteristics, and surgical characteristics of the elective posterior lumbar fusion patient population

\begin{tabular}{|c|c|c|}
\hline Characteristic, N (\%) except where specified & Number of patients & $\%$ \\
\hline Total & 43,063 & \\
\hline \multicolumn{3}{|l|}{ Demographic characteristics } \\
\hline \multicolumn{3}{|l|}{ Age (years) at index date } \\
\hline Mean (SD) & $59.4(13.69)$ & \\
\hline Median (Range) & $61(18,85)$ & \\
\hline$\geq 18-55$ & 15,221 & 35.35 \\
\hline $56-65$ & 11,639 & 27.03 \\
\hline $66-75$ & 11,579 & 26.89 \\
\hline $76-<86$ & 4624 & 10.74 \\
\hline \multicolumn{3}{|l|}{ Race } \\
\hline White & 38,535 & 89.49 \\
\hline Black or African American & 2556 & 5.94 \\
\hline Asian & 223 & 0.52 \\
\hline Other/Unknown & 1749 & 4.06 \\
\hline \multicolumn{3}{|l|}{ Sex } \\
\hline Male & 20,563 & 47.75 \\
\hline Female & 22,487 & 52.22 \\
\hline Unknown & 13 & 0.03 \\
\hline
\end{tabular}

Clinical \& surgical characteristics in 183-day baseline

Arthritis and other inflammation (or rheumatic events)

Rheumatoid arthritis

Reactive arthritis

Psoriatic arthroplasty

Spondyloarthritis, including ankylosing spondylitis

\section{Blood disorders}

Anemia/other anemia

Intracranial Hemorrhage

Gastrointestinal bleeding

\section{Cardiovascular events and/or conditions}

Acute myocardial infarction

Angina

Cardiac dysrhythmias

Stroke

Chronic ischemic disease

\section{Dementia}

\section{Diabetes}

Diabetes, type 1

Diabetes, type 2

\section{Digestive disorders}


Table 1 Baseline demographics, clinical characteristics, and surgical characteristics of the elective posterior lumbar fusion patient population (Continued)

\begin{tabular}{|c|c|c|}
\hline Characteristic, N (\%) except where specified & Number of patients & $\%$ \\
\hline Ulcerative colitis & 71 & 0.16 \\
\hline Peptic ulcer disease & 240 & 0.56 \\
\hline \multicolumn{3}{|l|}{ Hepatic disorders } \\
\hline Liver disease and cirrhosis & 607 & 1.41 \\
\hline \multicolumn{3}{|l|}{ Nervous system disorders } \\
\hline Guillain-Barre syndrome & 0 & 0.00 \\
\hline Multiple sclerosis & 105 & 0.24 \\
\hline \multicolumn{3}{|l|}{ Respiratory disorders } \\
\hline Asthma/wheezing/bronchospasm & 3353 & 7.79 \\
\hline Bronchitis/chronic obstructive pulmonary disease & 2315 & 5.38 \\
\hline Obstructive asthma & 1126 & 2.61 \\
\hline \multicolumn{3}{|l|}{ Surgical characteristics } \\
\hline Existing permanently implanted device or prosthesis at baseline & 1270 & 2.95 \\
\hline \multicolumn{3}{|l|}{ Total length of hospital stay } \\
\hline Mean (SD) & $3.8(3.4)$ & \\
\hline Median (Min, Max) & $3(1,90)$ & \\
\hline History of allogenic blood transfusion during surgery & 1 & 0.00 \\
\hline Revisional surgery on the same day as index surgery & 320 & 0.74 \\
\hline Use of implanted material during surgery on the same day as index surgery & 2667 & 6.19 \\
\hline \multicolumn{3}{|l|}{ Thrombotic events } \\
\hline Deep vein thrombosis & 386 & 0.90 \\
\hline Pulmonary embolism & 170 & 0.39 \\
\hline \multicolumn{3}{|l|}{ Thyroid disorders } \\
\hline Grave's disease & 37 & 0.09 \\
\hline Autoimmune thyroiditis & 55 & 0.13 \\
\hline Hyperthyroidism & 109 & 0.25 \\
\hline Hypothyroidism & 3455 & 8.02 \\
\hline Thyroiditis & 6 & 0.01 \\
\hline
\end{tabular}

higher incidences of stroke than women; for instance, the incidence of post-operative stroke during index hospitalization was $0.31 \%$ (95\% CI: $0.24,0.40 \%)$ for men and $0.28 \%$ (95\% CI: $0.21,0.36 \%$ ) for women. Additionally, black patients had higher stroke incidences than white, Asian, or other patients: the incidence of postoperative stroke $\leq 365$ days post-operation was $1.10 \%$ (95\% CI: $0.99,1.20 \%)$ among white adults, 1.65\% (95\% CI: $1.19,2.22 \%$ ) among black adults, $1.42 \%$ (95\% CI: $0.29,4.08 \%$ ) among Asian adults, and $0.92 \%$ (95\% CI: $0.53,1.49 \%$ ) among other adults.

The incidence of post-operative stroke was higher among patients with a history of type 2 diabetes than among patients without such history; for instance, the incidence of stroke was $2.08 \%$ (95\% CI: $1.73,2.47 \%$ ) for those with a history of type 2 diabetes and $0.97 \%$ (95\% CI: 0.87, 1.07\%) for those without such history $\leq 365$ days post-operation.
The incidence of post-operative stroke was much higher among patients with a history of stroke than among patients without a history of stroke during all risk windows. For example, post-operative stroke incidence during index hospitalization was 13.40\% (95\% CI: 9.71, 17.86\%) among those with a history of stroke and $0.20 \%$ (95\% CI: 0.16, $0.25 \%$ ) among those without such history. Lastly, patients with longer hospital stays had a higher incidence of stroke. However, it should be emphasized that these longer hospital stays could be a result of stroke instead of a reverse relationship (i.e., where stroke is the consequence of a longer hospital stay). Figure 1 displays relevant incidence results during index hospitalization and $\leq 365$ days post-operation stratified by certain demographic and clinical characteristics.

Detailed incidence rate information can be found in Additional file 1 . The crude incidence rate of stroke 


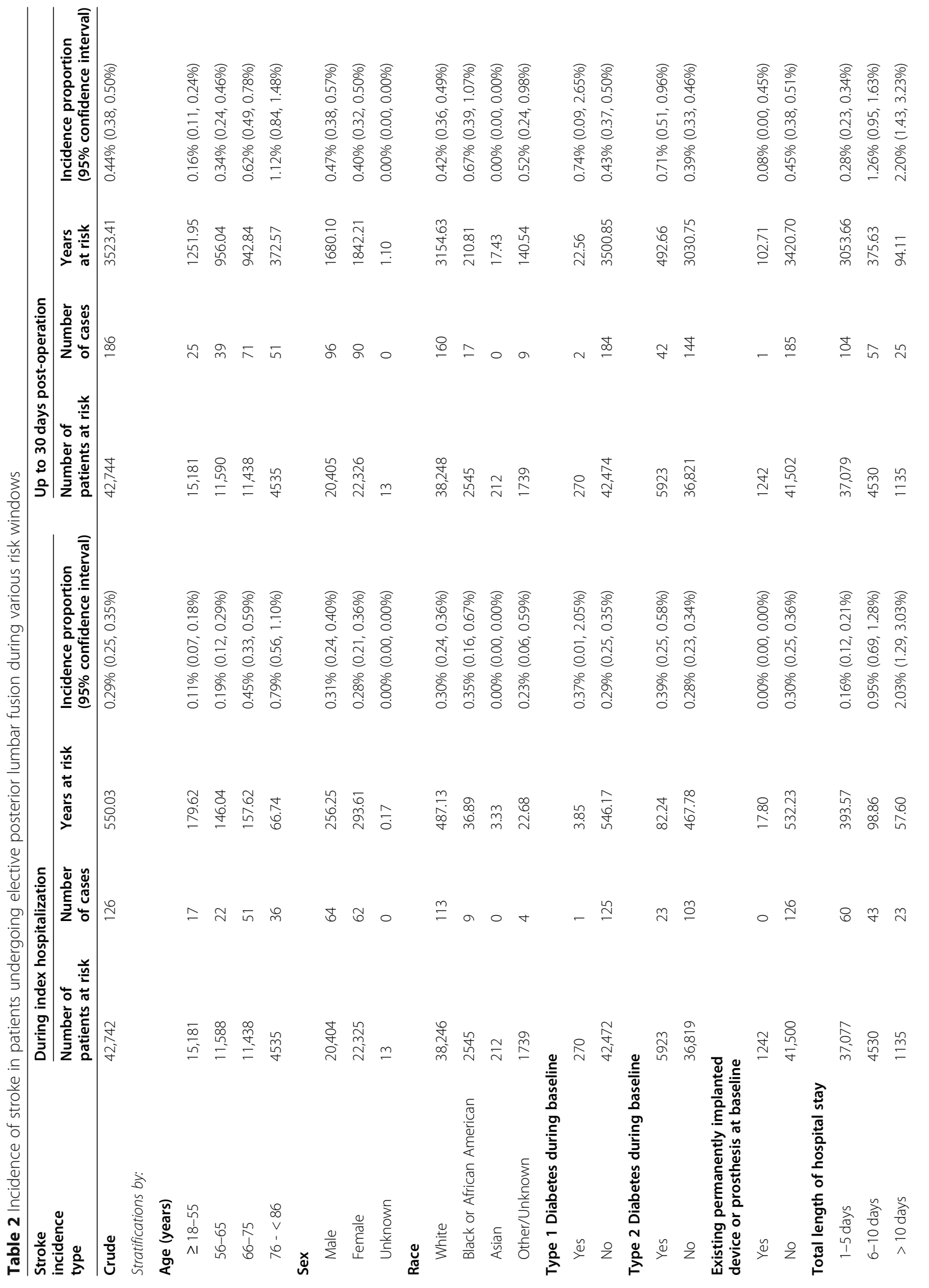




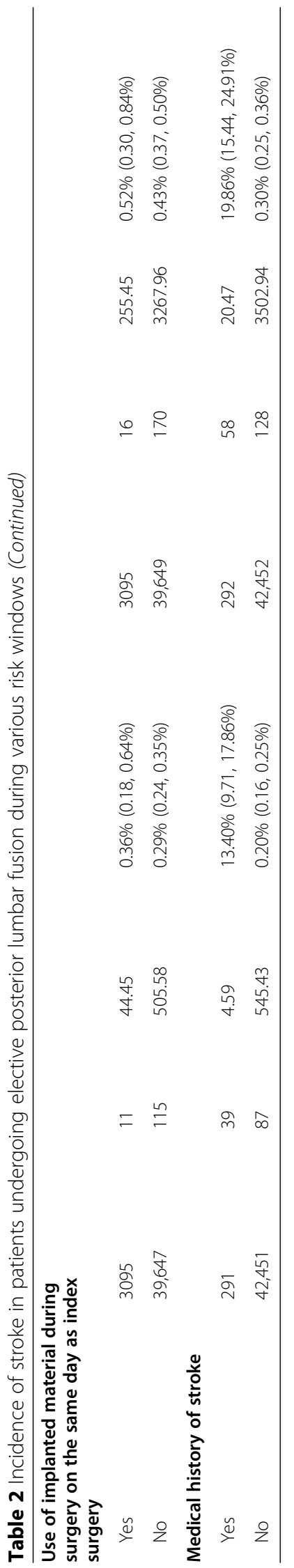




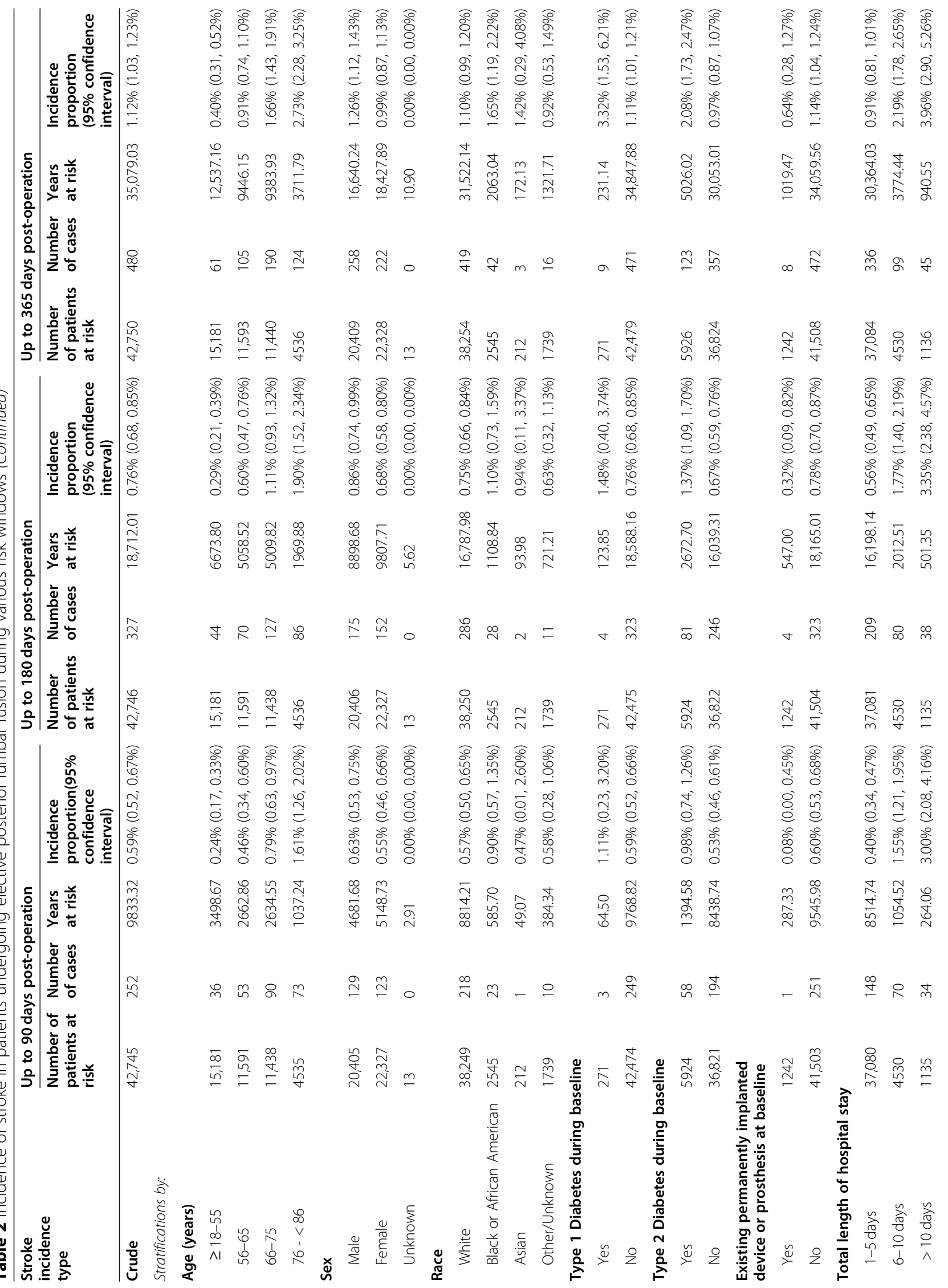




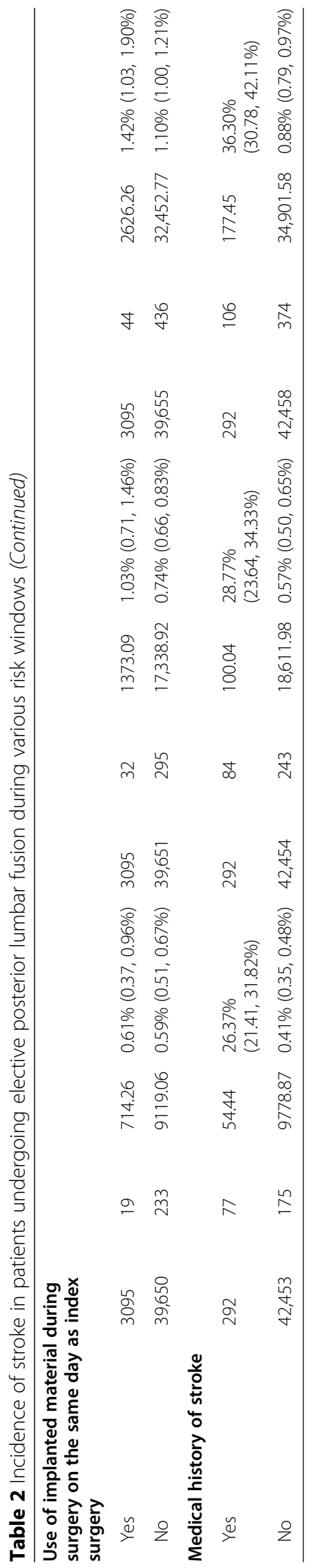




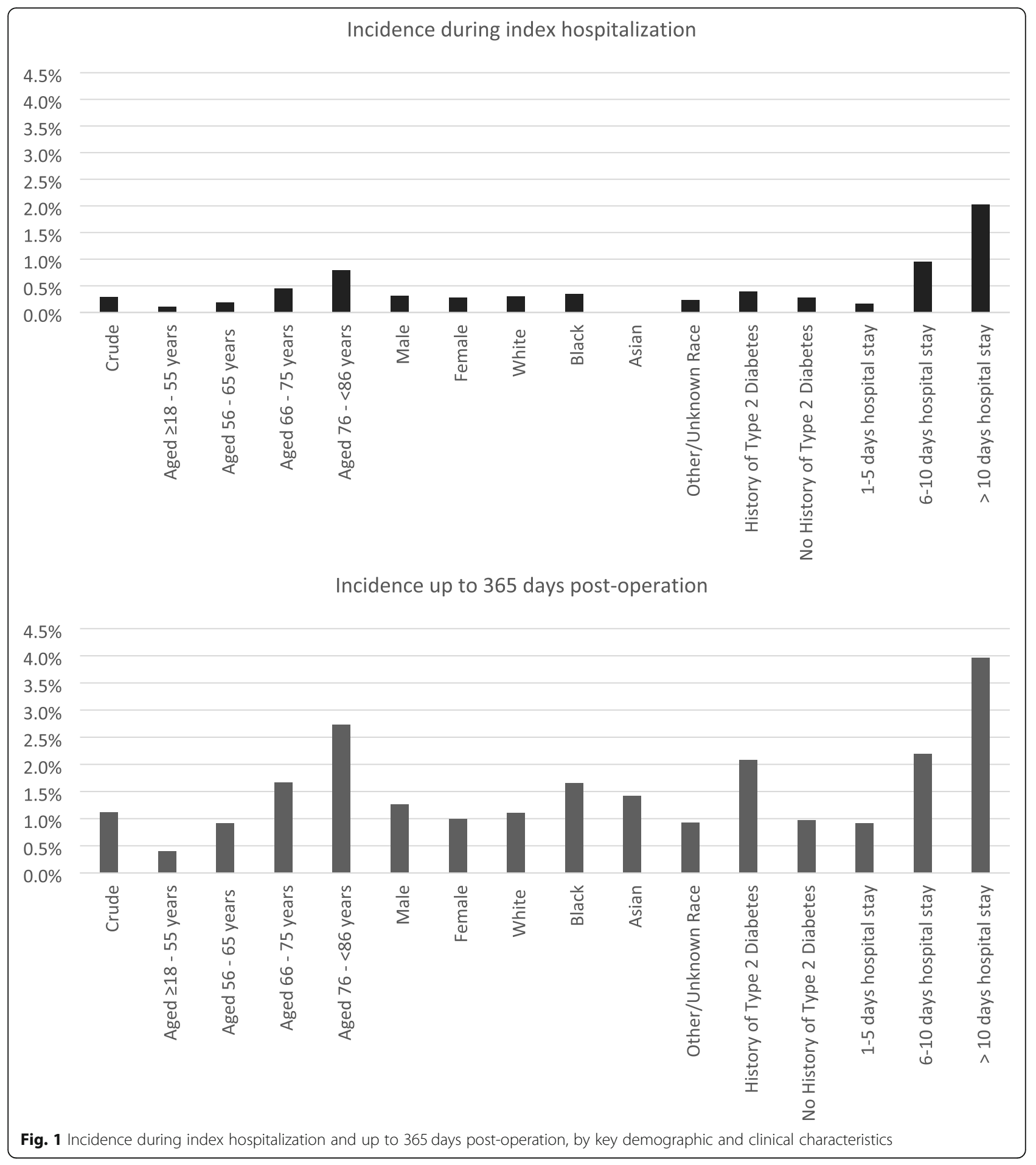

following elective PLF decreased consistently from index hospitalization to $\leq 365$ days post-operation; these incidence rates per 1000 person-years were 229.08 (95\% CI: 192.38, 272.78) during index hospitalization, 52.79 (95\% CI: 45.72, 60.95) $\leq 30$ days, 25.63 (95\% CI: 22.65, $28.99) \leq 90$ days, 17.48 (95\% CI: $15.68,19.48) \leq 180$ days, and 13.68 (95\% CI: $12.51,14.96) \leq 365$ days post-operation.

\section{Discussion}

\section{Summary}

This study identified 43,063 eligible patients who were relatively healthy and underwent inpatient elective PLF surgeries within the Optum EHR database. The incidence of stroke following elective PLF ranged from $0.29 \%$ (95\% CI: $0.25,0.35 \%)$ during index hospitalization 
to $1.12 \%$ (95\% CI: $1.03,1.23 \%) \leq 365$ days post-operation. When stratified by relevant demographic and clinical characteristics, we found that age, race, type 2 diabetes status, and stroke history were associated with stroke incidence; more specifically, PLF patients who were older, black, type 2 diabetic, or had a history of stroke had increased risk of post-operative stroke.

\section{Stroke incidence}

Minhas et al. examined the incidence of peri-operative cerebrovascular accidents (CVAs) among patients undergoing elective orthopedic procedures from 2006 to 2012 within the National Surgical Quality Improvement Program (NSQIP) database and reported that the 30-day incidence of CVA was $0.35 \%$ for single-level/multilevel PLF $(n=2895)$ [10]. In our study, a 30-day incidence for post-operative stroke of $0.44 \%$ (95\% CI: $0.38,0.50 \%$ ) was observed; however, it should be noted the authors defined their procedures using Current Procedure Terminology (CPT) codes and their definition for CVA was based on medical record review [10]. In a 2012 retrospective database study, 2015 PLF patients were identified from a nationwide Taiwanese cohort from 2000 to 2005 using The National Health Insurance Research Database and followed up for 3 years. The incidence rate of stroke per 1000 person-years was 10.22 (95\% CI: 7.94, 13.17). In their study, Wu et al. used ICD9-CM codes 430-435 for stroke and ICD-9-PCS codes 81.0 and 81.38 to identify PLF [11]. The incidence rate of stroke per 1000 person-years in our study was 13.68 $(95 \%$ CI: $12.51,14.96) \leq 365$ days post-operation, which was in line with their finding.

A 2014 retrospective cohort study performed by Marquez-Lara et al. used the Nationwide Inpatient Sample (NIS) database from 2002 to 2011 to identify patients undergoing elective lumbar fusion procedures and found a post-operative CVA incidence of $0.15 \%$ among the PLF patients $(n=214,837)$ [11]. In our study, the incidence of stroke following elective PLF ranged from $0.29 \%$ (95\% CI: $0.25,0.35 \%$ ) to $1.12 \%$ (95\% CI: 1.03 , $1.23 \%)$. It should be noted that only patients with ICD-9 code 81.08 were included and that CVA was defined with only one ICD-9 code (997.02) in their study. However, the researchers also found that increased length of hospital stay was associated with post-operative CVA [12]. Furthermore, a variety of studies examined 30-day outcomes following lumbar spinal fusion within both the NIS and NSQIP databases and generally found that the 30-day overall incidence of post-operative stroke was about $0.20 \%[6-9,13]$.

Our finding that the risk of stroke increased with age was consistent with the literature within the general population [14]. Furthermore, studies evaluating the risk of stroke among adults undergoing lumbar spinal fusion also found an association between increased age and the risk of stroke [10, 12, 15]. With regards to sex, Minhas et al. and Marquez-Lara et al. found no statistically significant difference in the sex-specific incidence of stroke $[10,12]$, which is in line with our findings. Stratified analyses revealed that black patients had a higher stroke incidence compared to other ethnic groups. This finding is consistent with the literature as numerous studies have illustrated that black patients have significantly higher risk of stroke in the general population [16-18]. Among populations undergoing elective PLF though, there was no published data on the incidence of postoperative stroke by race.

With regards to the other subgroups, limited information among PLF patients is available in the literature. However, Minhas et al. reported that patients with insulin-dependent diabetes mellitus (IDDM) had 3.08 times the odds of a post-operative CVA compared to those without IDDM [10]. Furthermore, recent reviews have demonstrated that diabetes mellitus is an established risk factor for stroke in the general population $[19,20]$. Thus, our finding that post-operative stroke incidence was higher among patients with a history of type 2 diabetes is consistent with the literature. Lastly, it is known that the incidence of stroke among those with a medical history of stroke is increased (i.e., there is a high risk of recurrent stroke) $[19,20]$; our results are thus in line with the standard medical knowledge regarding recurrent stroke.

\section{Implications and relevance}

As peri-operative stroke complications are associated with longer hospitalizations and increased hospital costs in addition to long-term complications such as epilepsy, depression, and pain $[4,12,21-26]$, these results suggest that appropriate stroke risk management prior to PLF may be needed for patients who are older, black, type 2 diabetic, and/or have a history of stroke. Lad et al. reached similar conclusions and stated that African American patients were more likely to experience postoperative complications of any kind for lumbar stenosis, even after adjusting for length of hospital stay, comorbidities, sex, and age [27]. Despite controversies surrounding appropriate peri-operative management of complicated medication regimens among elderly patients, healthcare providers should ensure that modifiable stroke risks are controlled and should include any concerns in discussions with their patients [28]. With regard to undiagnosed diabetes, a 2017 review by Epstein recommended routine pre-operative screening for diabetes with HbA1c levels among spinal surgery patients to facilitate pre-operative, intra-operative, and post-operative management [29]. However, the feasibility of such an approach would require that an appropriate referral mechanism already be in place. 
Although anticoagulants might be a suitable prophylaxis to prevent stroke in a general surgical setting, it should be highlighted that patients undergoing spinal surgery while under anticoagulation therapy are at risk of developing bleeding complications [30]. A 2020 review of anticoagulation and spine therapy by Porto et al. stated that current practice suggests holding warfarin until international normalized ratio $<1.4$, anti-Xa drugs for 48 to $72 \mathrm{~h}, 12$ to $24 \mathrm{~h}$ for low-molecular-weight heparin, and 4 to $24 \mathrm{~h}$ for heparin, before surgery. For antiplatelet agents, current practice indicated that they can be stopped for 1 to 3 days prior to operation $(81-500 \mathrm{mg}$ ) but must be stopped for 1 week for doses $>1 \mathrm{~g} / \mathrm{d}$. Current guidelines also recommended Plavix be discontinued for 5 to 7 days to prevent complications. Nonetheless, randomized control trials are needed in order to provide definitive guidance [31].

Moreover, this study provides additional information about stroke in a variety of risk windows. Most studies identified in the literature analyzed stroke events during index hospitalization or in the 30- or 90-day risk windows; our study thus builds on previous work by not only estimating stroke incidences during index hospitalization and the 30 - and 90-day risk windows but also by generating data on stroke incidence in the 180- and 365-day risk windows. Lastly, our study adds to the existing literature about stroke incidence by presenting such information in the form of incidence rates (see Additional file 1); most of the stroke incidence information in the literature is presented in the form of incidence proportions, and thus there is a paucity of data in the form of incidence rates.

\section{Variable and database considerations}

A 2012 review by Andrade et al. examined the validity of algorithms for identifying CVAs using administrative/ claims data among 35 identified studies and ultimately concluded that the algorithms and definitions used to identify CVAs using administrative/claims data differ greatly in the published literature. However, the authors determined that studies reported the highest positive predictive values for inpatient ICD-9 codes 430.x, 431.x, 434.x, and 436.x for acute stroke while algorithms that included ICD-9 codes 433.× 1, 434 (excluding 434.×0), and 436 performed well (85\% or higher) for transient ischemic stroke [32].

Lastly, it is noteworthy that our study used Optum EHR while most studies in the literature used NSQIP or NIS. Because of differences in these data sources, it may not be surprising that our results would not exactly align with the incidence information found in the literature. For instance, a 2016 study evaluated the variability in standard outcomes of PLF between the University HealthSystem Consortium (UHC) and the NIS and found that the databases had similar patient populations undergoing PLF, but that the UHC database reported significantly higher complication rates and longer lengths of hospital [33]. Additionally, recent studies have also shown that certain variables have changed over time within both NIS and NSQIP [9, 15]; thus, even comparisons within the same database can be fraught.

\section{Strengths and limitations}

The Optum EHR database has both inpatient and outpatient data as well as a large sample size that enabled us to generate real-world incidence estimates that are generalizable to a segment of the commercially insured US population (i.e., those in the Optum network). However, our patient population was selected to be relatively healthy, so this selection may affect the overall generalizability. Nonetheless, this study is one of the first to examine adverse outcomes among spinal surgery patients using an EHR database (as most studies in this area have used claims databases).

Still, it must be noted that EHR data were originally developed to improve patient care/modernize billing procedures and thus were not designed as research resources. As a result, EHR data tend to have more missing data (when compared to data obtained from clinical trials and/or prospective studies with primary data collection), and this missingness can potentially bias results [34]. However, given that elective surgery and stroke events generally require medical encounters, they would have been recorded in Optum EHR; therefore, the likelihood of missing information for these key variables would be very low. Like other studies utilizing secondary data sources without validation (e.g., medical chart review), exposure and outcome misclassification are also possible; diagnosis codes may have been incorrect or included as part of the diagnostic rule-out process rather than an indication of disease or surgery itself. Furthermore, patients may have sought healthcare outside Optum EHR prior to the index surgery, so it is possible that a patient developed a stroke prior to the index surgery; similarly, some incident events may have been missed if a patient sought care outside the system after surgery. Likewise, conditions identified during the baseline that do not require treatment or office visits (such as wheezing) tend to be systematically underrecorded in EHR databases; therefore, it is possible that this study only captured severe manifestations of such disorders. Additionally, as we used a broad set of ICD codes to identify stroke events, we may have overestimated its incidence.

Lastly, this study employed a descriptive analysis approach; thus, comparisons within stratified analyses may be subject to confounding factors that were not properly controlled. As a result, these comparisons must 
be interpreted with caution. Future studies in this area should consider multiple regression modeling and/or multivariable stratification techniques to better account for potential confounding.

\section{Conclusion}

This study estimated the incidence of stroke using an EHR database among adults undergoing elective PLF during various post-operative risk windows and among different subgroups. This incidence is slightly higher than that reported in the literature; however, the discrepancy is due to differences in the variable definitions, study populations, follow-up periods, and data sources between our study and those in the literature. Our results suggest that appropriate stroke risk modification prior to PLF may be of particular importance for patients who are older, black, type 2 diabetic, and/or have a history of stroke.

\section{Supplementary information}

Supplementary information accompanies this paper at https://doi.org/10. 1186/s12891-020-03631-5.

Additional file 1. Incidence rate of stroke in patients undergoing elective posterior lumbar fusion during various risk windows

\section{Abbreviations \\ Cl: Confidence interval; CPT: Current Procedure Terminology; \\ CVA: Cerebrovascular accident; EHR: Electronic healthcare record; \\ ICD: International Classification of Diseases; ICD-9-PCS: International Classification of Diseases, Ninth Revision, Procedure Classification System; ICD-9-CM: International Classification of Diseases, Ninth Revision, Clinical Modification; ICD-10: International Classification of Diseases, Tenth Revision; IDDM : Insulin-dependent diabetes mellitus; NIS: Nationwide Inpatient Sample; NSQIP: National Surgical Quality Improvement Program; PLF: Posterior lumbar fusion; UHC: University HealthSystem Consortium; US: United States}

\section{Acknowledgements}

Not applicable.

\section{Authors' contributions}

PJA, JM, CS, EB, AG, and KH contributed to the study design. PJA, KH, XZ, QL, $\mathrm{RS}$, and CW contributed to data analyses. PJA and KH drafted the manuscript with input from JM, CS, EB, AG, XZ, QL, RS, and CW. All authors read and approved the final manuscript.

\section{Funding}

This work was funded by Pfizer Inc.

\section{Availability of data and materials}

The data that support the findings of this study are available from Optum but restrictions apply to the availability of these data, which were used under license for the current study, and so are not publicly available. Data are however available from the authors upon reasonable request and with permission of Optum.

\section{Ethics approval and consent to participate}

As this study involved anonymized structured data, which according to applicable legal requirements do not contain data subject to privacy laws, obtaining informed consent from patients was not required.

\section{Consent for publication}

Not applicable.

\section{Competing interests}

All authors are employees of Pfizer Inc., New York, NY, USA.

\section{Author details}

${ }^{1}$ Global Medical Epidemiology \& Big Data Analysis, Pfizer Inc, New York, NY, USA. ${ }^{2}$ Safety Surveillance Research, Pfizer Inc, New York, NY, USA. ${ }^{3}$ Vaccine Research \& Development, Pfizer Inc, Pearl River, NY, USA. ${ }^{4}$ Global Medical Epidemiology \& Big Data Analysis, Pfizer Inc, Collegeville, PA, USA.

Received: 9 November 2019 Accepted: 3 September 2020

Published online: 14 September 2020

\section{References}

1. GBD 2016 Stroke Collaborators. Global, regional, and national burden of stroke, 1990-2016: a systematic analysis for the Global Burden of Disease Study 2016. Lancet Neurol. 2019;18(5):439-458. https://doi.org/10.1016/ S1474-4422(19)30034-1.

2. Rajsic S, Gothe H, Borba HH, Sroczynski G, Vujicic J, Toell T, et al. Economic burden of stroke: a systematic review on post-stroke care. Eur J Health Econ 2019 Feb;20(1):107-134. https://doi.org/https://doi.org/10.1007/s10198-0180984-0. Epub 2018 Jun 16.

3. Yang F, Zhao J, Xu H. Characteristics of hemorrhagic stroke following spine and joint surgeries. Biomed Res Int 2017:5390839. https://doi.org/10.1155/ $2017 / 5390839$.

4. Martin BI, Mirza SK, Spina N, Spiker WR, Lawrence B, Brodke DS. Trends in lumbar fusion procedures rates and associated hospital costs for degenerative spinal diseases in the United States, 2004 to 2015. Spine (Phila Pa 1976) 2019:44(5):369-376. https://doi.org/10.1097/BRS.0000000000002822.

5. Etzioni DA, Liu JH, Maggard MA, Ko CY. The aging population and its impact on the surgery workforce. Ann Surg 2003;238(2):170-177. https://doi.org/10.1097/01.SLA.0000081085.98792.3d.

6. Bronheim RS, Oermann EK, Cho SK, Caridi JM. Coagulation profile as a risk factor for 30-day morbidity and mortality following posterior lumbar fusion. Spine (Phila Pa 1976) 2017:42(12):950-957. https://doi.org/10.1097/BRS. 0000000000001935.

7. Chung AS, Campbell D, Waldrop R, Crandall D. Metabolic syndrome and 30day outcomes in elective lumbar spinal fusion. Spine (Phila Pa 1976) 2018; 43(9):661-666. https://doi.org/10.1097/BRS.0000000000002397.

8. Basques BA, Diaz-Collado PJ, Geddes BJ, Samuel AM, Lukasiewicz AM, Webb ML et al. Primary and revision posterior lumbar fusion have similar shortterm complication rates. Spine (Phila Pa 1976) 2016;41(2):E101-E106. https://doi.org/10.1097/BRS.0000000000001094.

9. Shultz BN, Bovonratwet P, Ondeck NT, Ottesen TD, McLynn RP, Grauer JN. Evaluating the effect of growing patient numbers and changing data elements in the National Surgical Quality Improvement Program (NSQIP) database over the years: a study of posterior lumbar fusion outcomes. Spine J 2018;18(11):1982-1988. https://doi.org/10.1016/j.spinee.2018.03.016.

10. Minhas SV, Goyal P, Patel AA. What are the risk factors for cerebrovascular accidents after elective orthopaedic surgery? Clin Orthop Relat Res 2016;474(3):611-618. https://doi.org/10.1007/s11999015-4496-2

11. Wu JC, Chen YC, Liu L, Huang WC, Thien PF, Chen TJ et al. Lumbar spine fusion surgery and stroke: a national cohort study. Eur Spine J 2012;21(12) 2680-2687. https://doi.org/10.1007/s00586-012-2405-X.

12. Marquez-Lara A, Nandyala SV, Fineberg SJ, Singh K. Cerebral vascular accidents after lumbar spine fusion. Spine (Phila Pa 1976) 2014;39(8):673677. https://doi.org/10.1097/BRS.0000000000000197.

13. Memstoudis SG, Kirksey M, Ma Y, Chiu L, Mazumdar M, Pumberger M et al. Metabolic syndrome and lumbar spine fusion surgery: epidemiology and perioperative outcomes. Spine (Phila Pa 1976) 2012;37(11):989-995. https://doi.org/10.1097/BRS.0b013e31823a3a13.

14. Kelly-Hayes M. Influence of age and health behaviors on stroke risk: lessons from longitudinal studies. J Am Geriatr Soc 2010;58 Suppl 2:S325-S328. https://doi.org/10.1111/j.1532-5415.2010.02915.x.

15. Shen $Y$, Silverstein JC, Roth S. In-hospital complications and mortality after elective spinal fusion surgery in the United States: a study of the nationwide inpatient sample from 2001 to 2005. J Neruosurg Anesthesiol 2009;21(1):21-30. https://doi.org/10.1097/ANA.0b013e31818b47e9.

16. Cruz-Flores S, Rabinstein A, Biller J, Elkind MSV, Griffith P, Gorelick PB et al. Racial-ethnic disparities in stroke care: the American experience: a statement for healthcare professionals from the American Heart 
Association/American Stroke Association. Stroke. 2011;42:2091-2116. https://doi.org/10.1161/STR.0b013e3182213e24.

17. Park JH, Ovbiagele B. Association of black race with recurrent stroke risk. J Neurol Sci 2016;365:203-206. https://doi.org/https://doi.org/10.1016/.jns. 2016.04.012.

18. Mozaffarian D, Benjamin EJ, Go AS, Arnett DK, Blaha MJ, Cushman M et al. Heart disease and stroke statistics - 2015 update: a report from the American Heart Association. Circulation. 2015;131:e29-e322. https://doi.org/ 10.1161/CIR.0000000000000152.

19. Hankey GJ. Stroke. Lancet. 2017;389(10069):641-654. https://doi.org/10.1016/ S0140-6736(16)30962-X.

20. Isabel C, Calvet D, Mas JL. Stroke prevention. Presse Med 2016;45(12 Pt 2): e457-e471. https://doi.org/10.1016/.J.lpm.2016.10.009.

21. Cassinelli EH, Eubanks J, Vogt M, Furey C, Yoo J, Bohlman HH. Risk factors for the development of perioperative complications in elderly patients undergoing lumbar decompression and arthrodesis for spinal stenosis: an analysis of 166 patients. Spine (Phila Pa 1976) 2007;32(2):230-235. https://doi.org/10.1097/01.brs.0000251918.19508.b3.

22. Harrison RA, Field TS. Post stroke pain: identification, assessment, and therapy. Cerebovasc Dis 2015;39(3-4):190-201. https://doi.org/10.1159/ 000375397. Epub 2015 Mar 5.

23. Lambat MP, Glassman SD, Carreon LY. Impact of perioperative complications on clinical outcome scores in lumbar fusion surgery. J Neurosurg Spine 2013 Mar;18(3):265-268. https://doi.org/10.3171/2012.12. SPINE12805. Epub 2013 Jan 4.

24. Robinson RG, Jorge RE. Post-stroke depression: a review. Am J Psychiatry 2016;173(3):221-231. https:/doi.org/10.1176/appi.ajp.2015.15030363. Epub 2015 Dec 18.

25. Tanaka T, Ihara M. Post-stroke epilepsy. Neurochem Int 2017 Jul;107:219-228. https:/doi.org/10.1016/..neuint.2017.02.002. Epub 2017 Feb 12.

26. Zorowitz RD, Gillard PJ, Brainin M. Poststroke spasticity: sequelae and burden on stroke survivors and caregivers. Neurology. 2013 Jan 15;80(3 Suppl 2):S45-S52. https://doi.org/10.1212/WNL.0b013e3182764c86

27. Lad SP, Bagley JH, Kenney KT, Ugiliweneza B, Kong M, Bagley CA, et al. Racial disparities in outcomes of spinal surgery for lumbar stenosis. Spine (Phila Pa 1976) 2013;38(11):927-935. https://doi.org/10.1097/BRS. 0b013e31828165f9.

28. Brallier JW, Deiner $S$. The elderly spine surgery patient: pre- and intraoperative Management of Drug Therapy. Drugs Aging 2015;32(8):601-609. https://doi.org/10.1007/s40266-015-0278-5.

29. Epstein NE. Predominantly negative impact of diabetes on spinal surgery: a review and recommendation for better preoperative screening. Surg Neurol Int 2017;8:107. https://doi.org/10.4103/sni.sni_101_17. eCollection 2017.

30. Akhavan-Sigari R, Rohde V, Abili M. Continuation of medically necessary platelet aggregation inhibitors - acetylsalicylic acid and clopidogrel - during surgery for spinal degenerative disorders: results in 100 patients. Surg Neurol Int 2014 Aug 28:5(Suppl 7):S376-S379. https://doi.org/10.4103/21527806.139675. eCollection 2014

31. Porto GBF, Jeffrey W, Alvarado A, Arnold PM, Buchholz AL. Anticoagulation and Spine Surgery. Global Spine J. 2020 10(1_suppl), 53S-64S. https://doi. org/10.1177/2192568219852051.

32. Andrade SE, Harrold LR, Tjia J, Cutrona SL, Saczynski, Dodd KS et al. A systematic review of validated methods for identifying cerebrovascular accident or transient ischemic attack using administrative data. Pharmacoepidemiol Drug Saf. 2012;21 Suppl 1:100-128. https://doi.org/10. 1002/pds.2312.

33. Joseph JR, Smith BW, Park P. Variability in standard outcomes of posterior lumbar fusion determined by national databases. World Neurosurg 2017;97: 236-240. https://doi.org/10.1016/j.wneu.2016.09.117.

34. Beaulieu-Jones BK, Lavage DR, Snyder JW, Moore JH, Pendergrass SA, Bauer CR. Characterizing and managing missing structured data in electronic health records: data analysis. JMIR Med Inform 2018;6(1):e11. https://doi.org/ 10.2196/medinform.8960.

\section{Publisher's Note}

Springer Nature remains neutral with regard to jurisdictional claims in published maps and institutional affiliations.

\section{Ready to submit your research? Choose BMC and benefit from:}

- fast, convenient online submission

- thorough peer review by experienced researchers in your field

- rapid publication on acceptance

- support for research data, including large and complex data types

- gold Open Access which fosters wider collaboration and increased citations

- maximum visibility for your research: over $100 \mathrm{M}$ website views per year

At BMC, research is always in progress.

Learn more biomedcentral.com/submissions 